\title{
ESTRATÉGIAS DE PREVENÇÃO CONTRA OS INCÊNDIOS FLORESTAIS
}

\author{
Guido Assunção Ribeiro ${ }^{1}$
}

\section{INTRODUÇÃO}

Os incêndios florestais constituem em um dos mais danosos eventos que provocam alterações nas formações vegetais, sejam elas naturais ou plantadas. Muitas são as causas de sua origem, entretanto, as mais freqüentes e preocupantes reúnem-se em pequeno grupo onde o homem se destaca, principalmente por meio de suas atividades no meio rural.

Os agentes causadores de danos ao ambiente apresentam diferenças significativas entre países, ou até mesmo entre regiões, e podem ser representados, principalmente, pelas intempéries climáticas, pelas doenças, pelas pragas e pelas atividades antrópicas. Dentre as atividades do homem, o maior agente de danos tem sido atribuído ao uso irresponsável do fogo, o qual tem provocado transformações de difícil compreensão e muitas vezes desconhecidas, dada a complexidade dos fatores envolvidos no processo da combustão e do comportamento do fogo.

A ocorrência do fogo depende de alguns fatores que permitirão o início da reação da combustão e a sua continuação dependerá, principalmente, da energia potencial armazenada no material combustível e do comportamento do fogo, comandado pelas características do material combustível (Ribeiro e Soares, 1998), pelo relevo e pelas condições meteorológicas. Entretanto, o potencial de risco pode chegar a limites altíssimos sem contudo haver a ocorrência do incêndio. Sabese que a combustão é nos momentos iniciais uma reação endotérmica, ou seja, ela necessita de uma fonte de energia externa para se iniciar. Após isso, ela se transforma numa reação exotérmica e continuará até que outros fatores interfiram no processo, interrompendo a reação. Portanto, um dos principais pontos de atuação dos trabalhos de prevenção está no controle ou no monitoramento da fonte inicial de energia, que nada mais é do que as causas dos incêndios florestais.

Os riscos sempre estiveram presentes na vida do homem. A Terra é de fato um planeta dinâmico, pleno de energia e onde as mudanças são constantes. As catástrofes surgem, muita vezes, de forma inesperada e não raramente são acompanhadas de perda de vidas humanas, o que assusta e causa sofrimento na população e altera a sua rotina. Além disso, há também perdas ou danos materiais, de dimensões incalculáveis, com conseqüências negativas para um país e sua população.

O risco de fogo ao ambiente, que pode ser traduzido como a vulnerabilidade da vegetação, viva ou morta, pode ser estimado conforme a teoria de riscos, a qual baseia-se em dados históricos de ocorrências para determinada região. Assim sendo, a prevenção de qualquer sinistro torna-se uma tarefa tão mais segura quanto mais precisa forem as informações armazenadas no banco de dados. Uma prevenção somente é efetiva se acompanhada de um planejamento sério, onde deve-se analisar os dados históricos, estimando-se a probabilidade de ocorrência de fogo e implementando medidas mitigadoras para impedir tais ocorrências.

Dentre todas ações, a conscientização da população, relativa aos riscos de incêndio florestal, constitui-se numa tarefa fundamental. $\mathrm{O}$ objetivo principal do plano de prevenção deve estar voltado para eliminar ou minimizar o risco por meio de tecnologias e procedimentos planejados para alcançar os resultados desejados.

O objetivo principal desse trabalho foi levantar a discussão e mostrar a importância das atividades de prevenção contra os incêndios florestais, dentro do contexto de um plano de segurança de uma floresta cultivada ou natural. Esta apresentação visa, também, abordar algumas estratégias de prevenção e levantar a discussão sobre a importância da eliminação ou minimização dos perigos de sinistros da magnitude dos incêndios florestais. Estes procedimentos trazem tranqüilidade para os tomadores de decisão uma vez que diminui os riscos financeiros causados pelas perdas de produtos comerciais ou da biodiversidade e menor risco à integridade física das pessoas envolvidas.

\footnotetext{
${ }^{1}$ Departamento de Engenharia Florestal, Universidade Federal de Viçosa
} 


\section{Queima controlada}

De acordo com Ribeiro e Bonfim (2000), queima controlada é uma ação planejada, com objetivos claramente definidos, cujos efeitos são esperados dentro de limites aceitáveis. Todos os fatores relacionados com o comportamento do fogo devem ser conhecidos, para que os resultados negativos sejam mantidos dentro da faixa mínima planejada. Ao contrário da queima controlada, o incêndio florestal é um evento casual, com efeitos imprevisíveis, pois sua ocorrência se dá sob condições de clima e de material combustível propícias para a combustão. Num incêndio florestal nenhuma variável está sob controle e pode resultar numa situação irreversível do sítio de ocorrência.

Paralelamente aos incêndios florestais, que são na maioria das vezes provocado pelo homem, o fogo é empregado no meio rural como um instrumento de manejo da terra. Assim sendo, ele é considerado uma técnica como qualquer outra, que produz efeitos benéficos e maléficos no ambiente onde é aplicada. Constitui-se, assim, uma prática alternativa no meio rural, por ser eficiente e muitas vezes econômica sob o ponto de vista dos produtores (Ribeiro, 2000).

Ao lado das questões econômicas, essa prática envolve, também, aspectos culturais. As técnicas agrícolas de manejo da terra são repassadas de pai para filho ao longo do tempo. O fogo, por exemplo, é utilizado pelos agricultores por ser considerado um meio prático para diversas finalidades, como limpar o terreno a fim de eliminar restos vegetais; favorecer a disponibilidade de nutrientes ao solo e, conseqüentemente, aumentar sua capacidade produtiva; reduzir a incidência de pragas e doenças e reduzir gastos com mão-de-obra e com os custos de produção.

A queima controlada deve ser empregada mediante um planejamento prévio onde os aspectos diretamente relacionados com o seu comportamento devem ser conhecidos como o clima, o material combustível e todas as suas variações, a topografia, as técnicas de ignição, as ferramentas e equipamentos apropriados na sua aplicação, dentre outros.

O conceito de queima controlada é, dessa forma, muito mais amplo e vai muito além do simples fato de circunscrever o fogo em uma área, por meio de um aceiro. A não utilização de qualquer critério técnico que tenha relação com o comportamento do fogo, para se autorizar a queima controlada, é, provavelmente, um dos mais graves problemas com relação ao seu emprego no manejo da terra. Por outro lado, ao se analisar os aspectos da tradição e da cultura, percebe-se que muitas justificativas infundadas têm sido utilizadas para justificar o uso do fogo. Neste contexto, é necessário um forte trabalho de educação ambiental em que o processo da educação seja completo, isto é, não basta apenas conscientizar o cidadão sobre os perigos e as conseqüências do uso do fogo, é necessário fornecer alternativas, mas que estejam ao seu alcance principalmente em termos econômicos.

Apesar de os efeitos provocados pelas queimadas ou pelos incêndios florestais, sobre qualquer formação vegetal, gerar grande polêmica no meio técnico ou científico, pode-se perceber que é possível fazer uso do fogo de uma forma racional, minimizando seus efeitos maléficos e otimizando os benefícios. Como qualquer outra técnica, o fogo não deve ser empregado em todas as situações pois é necessário conhecer o histórico da área a ser manejada, os objetivos da queima, o tipo de solo, o ecossistema envolvido, o regime de fogo anterior, a presença de fauna ou flora endêmicas, a proximidade de centros urbanos, redes de transmissão de energia elétrica e áreas de proteção especial bem como a dispersão de fumaças, etc.

A utilização do fogo, como ferramenta auxiliar no meio agrícola e florestal, tem sido objeto de estudo em vários países, bem como um procedimento cujo efeito no ambiente é gerador de muita polêmica. Para as condições brasileiras tais estudos são, ainda, incipientes além da pouca divulgação das informações existentes. Muitas pesquisas são necessárias para se conhecer as inter-relações entre a técnica e a periodicidade de queima, as condições meteorológicas e o material combustível formado pela complexidade, que são as formações vegetais (Batista, 2000), bem como as medidas de segurança a serem adotadas para manter o fogo dentro dos limites planejados. Por causa disso, o fogo utilizado como queima controlada tem causado grandes incêndios florestais pelo desconhecimento e pela falta de compromisso de seu usuário com relação aos cuidados mínimos, visando apenas a obtenção dos objetivos da queima (Ribeiro, 2000).

É sabido que a queima controlada mal conduzida têm sido a grande causa de incêndios florestais em todo o Brasil. Segundo Soares (1988), os incêndios florestais estão intimamente 
relacionados com as condições meteorológicas, confirmando-se, na prática, que a maioria dos incêndios acontecem na estação seca do ano e mais precisamente, imediatamente antes das primeiras chuvas. Como já discutido acima, não basta que parte dos fatores que influenciam a ocorrência e determinam o comportamento do fogo estejam favoráveis à combustão. Se não houver a causa, a vulnerabilidade ao fogo continua crescente mas sem a chama inicial não haverá ocorrência de incêndio. É neste momento que a queima controlada mal conduzida se transforma na grande vilã, sendo a causadora de grandes incêndios florestais todos os anos.

Embora Batista e Soares (1988) argumentem que a queima controlada pode trazer grande contribuição para os planos de proteção, resultando na diminuição dos riscos de incêndios, em muitas situações o uso dessa técnica é impossível ou de difícil aplicação, como nas margens de rodovias e sob as linhas de transmissão de energia elétrica. Associado a isto, a queima controlada realizada fora dos padrões conceituais deve ser enquadrada como um procedimento ilegal e o responsável pela ação fica sujeito às penalidades civis e criminais.

\section{Estratégias de prevenção contra os incêndios florestais}

Incêndios catastróficos têm ameaçado a vida humana e propriedades em todo o mundo. Segundo Linn e Harlow (1998), atualmente os manejadores estão se conscientizando que a supressão do fogo não pode ser feita indefinidamente e que o fogo faz parte da natureza.

Por outro lado, torna-se mais evidente a cada dia a necessidade de se planejar a proteção contra os incêndios florestais, pois além de se promover a redução do número de ocorrências, um sistema organizado encontra-se disponível para acionar o primeiro ataque a qualquer momento. $\mathrm{O}$ planejamento das ações de proteção contribuirá para a redução dos custos de combate, a área queimada, os riscos de acidente com pessoal e os efeitos sobre todos os componentes dos ecossistemas atingidos.

Os planos de proteção contra incêndios florestais, à semelhança do planejamento de qualquer atividade, dependem dos objetivos a serem atingidos. Pyne (1984) cita, por exemplo, que os planos podem ser estratégicos, quando estão relacionados com grandes áreas e longo período de tempo, ou podem ser operacionais, quando relacionados com atividades de rotina. Nesse sentido, os planos podem ser elaborados em vários níveis de abrangência.

Os planos de proteção podem ser gerais ou específicos, ou seja, eles podem contemplar todas as operações para proteção contra o fogo ou serem direcionados exclusivamente para a prevenção, para a detecção, para a pré-supressão ou manejo do material combustível, para a queima controlada ou para a supressão ou combate ao fogo propriamente dito. Com base no fluxograma apresentado por Soares (1996), a prevenção é um item integrante do Plano de Proteção contra Incêndios Florestais. A prevenção pode ser trabalhada individualmente em termos de planejamento mas ela deve integrar o plano maior, seja ele um plano estratégico ou operacional.

A complexidade do sistema de prevenção e combate aos incêndios florestais depende dos objetivos a serem alcançados, das peculiaridades da região a ser protegida e da capacidade de investimento na proteção.

A prevenção, pelo fato de preceder as demais ações para controle dos incêndios florestais, tem por objetivo principal a adoção de medidas que procuram eliminar a origem ou a causa dos incêndios bem como reduzir os riscos de propagação do fogo, constituindo-se numa das mais importantes etapas do plano de proteção. A experiência mostra que os investimentos realizados com as ações preventivas são compensadores em relação aos custos de combate, os quais envolvem riscos de acidentes e desgaste físico dos brigadistas, desgaste e perda de ferramentas e equipamentos, custos com transporte e apoio logístico, perdas econômicas reais do objeto da proteção e perdas devidas aos danos ambientais.

Os incêndios florestais somente chamam a atenção da população ou dos tomadores de decisão quando ocorrem em grandes proporções e de forma inesperada e destrutiva. O investimento em treinamento de pessoal, na aquisição de equipamentos e de produtos e na vigilância não mostra, num primeiro momento, um retorno econômico. Na maioria das vezes, as perdas que deixam de acontecer devido a estes investimentos não são consideradas como um ganho de um bom sistema de proteção. Quanto mais eficiente for este sistema, mais difícil fica a estimativa dos benefícios advindos da 
exclusão do fogo, ou seja, apesar de ser uma tarefa de difícil execução fica mais fácil avaliar os prejuízos provocados pelo fogo do que dimensionar os benefícios auferidos pelo plano de controle dos incêndios.

A prevenção contra os incêndios será tão mais eficiente quanto mais investimentos se fizer nas seguintes áreas:

\section{Educação Ambiental}

O objetivo básico da prevenção resume-se na implementação de ações para reduzir as causas e os riscos de propagação do fogo. As principais causas dos incêndios estão relacionadas com a atividade do homem no meio rural, podendo ser originada de uma ação involuntária ou por negligência, no caso dos incêndios culposos ou ser uma atitude planejada e criminosa no caso dos incêndios dolosos. Tanto num sentido quanto em outro, todas estas causas, a princípio, podem ser evitadas. Os meios a serem utilizados são as campanhas educativas, a aplicação da legislação ou de medidas coercitivas.

\section{Redução dos Riscos de Propagação do Fogo}

A redução dos riscos de propagação visa a adotar medidas prévias para evitar a propagação dos incêndios cuja origem não pode ser controlada, podendo ser usado para isto a construção de aceiros e o manejo do material combustível e técnicas mais recentes como a silvicultura preventiva.

\section{Vigilância ou Patrulhamento}

A vigilância pode ser fixa, móvel ou auxiliar. O grau de sofisticação pode variar desde o uso de animais de montaria até o de aeronaves, na vigilância móvel; o emprego de abrigos em pontos estratégicos até o de torres equipadas com sistemas automáticos de detecção, como sensores infravermelhos e câmaras de vídeo, na vigilância fixa, e a participação da sociedade civil, desde os transeuntes até a aviação comercial, na vigilância auxiliar.

\section{Treinamento de pessoal}

Envolve a capacitação do pessoal envolvido nos trabalhos de controle dos incêndios, sejam os responsáveis pela elaboração e execução do plano de prevenção, seja o pessoal que atua na "linha de fogo". O treinamento deve ser feito periodicamente, visando a harmonizar os trabalhos dentro e entre equipes, a utilizar as técnicas de combate adequadas e a utilizar as ferramentas e os equipamentos corretamente. $\mathrm{O}$ treinamento é fundamental para colocar as equipes a par de todos os problemas relacionados com as operações de comando, atividades de campo, reconhecimento da área, limitações materiais e humanos e riscos de acidentes.

\section{Equipamentos}

Os equipamentos podem ser tão simples quanto um abafador, ou tão sofisticados quanto as aeronaves desenvolvidas exclusivamente para este fim. Entretanto, não se deve ter em mente que o uso de um equipamento de tecnologia mais avançada substituirá um equipamento mais simples. Nenhum recurso deve ser menos empregado, porque na maioria das vezes eles são complementares. Por outro lado, a eficiência do plano de proteção contra os incêndios florestais é que garantirá a sua continuidade.

A decisão de aquisição de equipamentos é uma medida preventiva uma vez que possibilita os administradores a planejar as ações com base nos recursos disponíveis. O nível de sofisticação dependerá, conforme já mencionado anteriromente, do investimento realizado para atender ao plano de proteção contra os incêndios.

\section{Montagem de um banco de dados}

As estatísticas sobre a ocorrência de incêndios florestais não são limitantes para a implantação do plano de proteção, mas são fundamentais para o seu aprimoramento e sua manutenção.

Os registros estatísticos são essenciais por aumentar tanto a eficiência técnica quanto a econômica dos trabalhos. Os incêndios florestais têm características sazonais, o que leva a um planejamento diferenciado ao longo do ano, principalmente com relação às atividades de prevenção. 
Nesse sentido, conhecendo-se a época de maior ocorrência, as principais causas, as falhas do sistemas de proteção detectadas nos trabalhos anteriores é possível desenvolver ações com maior eficiência, obtendo melhores respostas a um custo operacional mais baixo.

\section{Formação de Parceria}

Os incêndios florestais não respeitam fronteiras administrativas nem políticas de uma região ou país. As ações de prevenção devem ser de todo cidadão uma vez que todos tem direito a um ambiente despoluído, conservado e sem riscos para qualquer forma de vida. Nesse sentido, exigir os direitos e cumprir seus deveres nada mais é do que um exercício de cidadania. Portanto, quanto mais organizada estiver a sociedade, anglobando o Poder Público, a Sociedade Civil Organizada, as Organizações Não Governamentais, as Organizações da Sociedade Civil de Interesse Público, as Empresas Privadas e o cidadão comum mais fácil torna-se a formação de parcerias para atacar um mal que atinge a todos e depende de todos para o sucesso de seu controle.

\section{REFERÊNCIAS}

BATISTA, A.C.; SOARES, R.V. Uso de indicadores na determinação de umidade do material combustível sob povoamento de Pinus taeda. Revista Floresta, n. 1-2, v. XVI. P. 19-25. 1988.

LIN, R.R.; HARLOW, F.H. Use of transport models for wildfire behaviour simulations. Associação para o Desenvolvimento da Aerodinâmica Industrial-ADAI : Luso, Coimbra, Portugal, 1998. Vol. I. p. 363-372.

PYNE, S.J. Introduction to Wildland Fire. Fire Management in the United States. New York: John Wiley \& Sons, 1984. 455 p.

RIBEIRO, G.A. Queima controlada. Universidade Federal de Viçosa, Viçosa, MG. 4 p. 2000 (Notas de Aulas)

RIBEIRO, G.A.; BONFIM, V.R. Incêndio Florestal versus queima controlada. Ação Ambiental, Viçosa, Ano II, n. 12, 2000. p. 8.

RIBEIRO, G.A.; SOARES, R.V. Caracterização do material combustível florestal e efeitos da queima controlada sobre sua redução em um povoamento de Eucalyptus viminalis. Cerne, Lavras, v. 4, n. 1, p. 57-72. 1998.

SOARES, R.V. Plano de proteção contra incêndios florestais. In: IV REUNIÃO TÉCNICA CONJUNTA FUPEF/SIF/IPEF E CURSO DE ATUALIZAÇÃO EM CONTROLE DE INCÊNDIOS FLORESTAIS (IV e II: 1996: Curitiba). Anais... Curitiba: FUPEF, 1996. P. 140-150.

SOARES, R.V. Perfil dos incêndios no Brasil, de 1984 a 1987. Revista Floresta, n.1-2, v. XVIII. P. 95-99. 1988. 